\title{
The economics of abrupt climate change
}

\author{
By CHARLES PERRINGS \\ Contact Environment Department, University of York, \\ Heslington, York YO10 5DD, UK (cap8@york.ac.uk)
}

Published online 22 July 2003

The US National Research Council defines abrupt climate change as a change of state that is sufficiently rapid and sufficiently widespread in its effects that economies are unprepared or incapable of adapting. This may be too restrictive a definition, but abrupt climate change does have implications for the choice between the main response options: mitigation (which reduces the risks of climate change) and adaptation (which reduces the costs of climate change). The paper argues that by

(i) increasing the costs of change and the potential growth of consumption, and

(ii) reducing the time to change,

abrupt climate change favours mitigation over adaptation.

Furthermore, because the implications of change are fundamentally uncertain and potentially very high, it favours a precautionary approach in which mitigation buys time for learning. Adaptation-oriented decision tools, such as scenario planning, are inappropriate in these circumstances. Hence learning implies the use of probabilistic models that include socioeconomic feedbacks.

Keywords: abrupt climate change; mitigation; adaptation; precautionary principle

\section{Introduction}

As an economic problem, climate change has a number of distinctive features. First, the climate is a global public good. Since no one country can be excluded from the benefits of mitigation by any other, every country has an incentive to 'free ride' on the mitigation actions of others. Second, the most important anthropogenic emissions behind climate change (principally carbon dioxide) are what are called stock pollutants: they build up in the system. One implication of this is that emissions control can take a long time to have any appreciable effect. If future costs and benefits are discounted at positive rates, this can mean that the present value of actions that pay off only in the far future may be quite small. Third, the system is characterized by multiple locally stable states. Small incremental changes can induce it to flip from one state into another in ways that can be either irreversible or only slowly reversible. This implies that policies relying on ex post adaptation or correction may be either ineffective (in the case of irreversibility) or effective only very slowly and at high cost

One contribution of 14 to a Discussion Meeting 'Abrupt climate change: evidence, mechanisms and implications'. 
(in the case of hysteresis). Fourth, future climate states are fundamentally uncertain. It is currently not possible to provide comprehensive probability density functions (PDFs) or confidence intervals for projections from the general circulation models at spatial and temporal scales that matter for national climate policy. Finally, interactions between the component parts of both the climate and the economic system are such that climate change and other policies are not independent. Policies directed at very different targets may have significant implications for climate change (Carraro 2002; Kaul et al. 2003).

The third feature of climate change - that the climate system can exist in many possible states - is the source of the abrupt regime shifts that are the focus of this issue. An example of immediate interest is the possibility that the North Atlantic thermohaline circulation will be interrupted. Such a regime shift could lower mean temperatures in the UK, Scandinavia and Iceland by up to $12{ }^{\circ} \mathrm{C}$, and lead to a commensurate increase in mean temperatures in the South Atlantic. I wish to consider what implications such abrupt change has for the way countries make policy decisions about the control of greenhouse-gas (GHG) emissions or investment in measures to reduce the cost of change.

In at least one case, the implication for response options is part of the definition of abrupt climate change. The US National Research Council, for example, defines abrupt climate change as a change of state that is sufficiently rapid and sufficiently widespread in its effects that economies are either unprepared or incapable of adapting (USNRC 2002). There are two ways that decision makers can respond to the prospect of any uncertain future event or process, including climate change. Mitigation involves actions that reduce the likelihood of the event or process. Adaptation involves actions that reduce the impact of the event or process without changing the likelihood that it will occur. There is no universally agreed standard use of these terms. For example, the World Bank (2001) uses 'risk reduction' to refer to action that reduces the likelihood of an event, and 'mitigation' to refer to action that reduces the cost of an event. Nevertheless, the climate-change literature tends to use mitigation and adaptation in the same sense as this paper. Mitigation in this sense always implies action before the event. Adaptation may involve actions taken before, during or after the event. Adaptation usually implies actions that reduce the expected damage of an event (such as the adoption of building standards that minimize earthquake damage), but it also includes actions that pool or transfer the risk of an event (such as insurance). Taken literally, the USNRC definition - that abrupt climate change precludes adaptation as a response-holds. Clearly, this is too restrictive. But the potential for abrupt climate change does have important implications for the choice between mitigation and adaptation.

The paper is organized into four sections. The following section reviews existing economic evaluations of the main policy-response options: mitigation and adaptation. It focuses on findings that are sensitive to the special features of abrupt climate change: the speed of change, the extent of the potential damage, and the level of uncertainty it engenders. The next section reconsiders the way in which economic decisions are made in the light of abrupt climate change. A final section evaluates abrupt climate change as a candidate for a precautionary response, and discusses the implications of abrupt climate change for the relative net benefits of the main response options. 


\section{Mitigation versus adaptation under abrupt climate change}

No country will undertake mitigation actions unless it is believed that those actions will affect the probability of climate change. That is, mitigation presupposes that anthropogenic emissions of GHGs are a significant part of the explanation for abrupt climate change, and that reducing the concentration of GHGs will affect the likelihood of such change talking place. Mitigation includes any actions to reduce emissions of $\mathrm{CO}_{2}$ (and other GHGs), or to increase carbon sequestration. Examples include carbon and other energy taxes, energy policies to reduce dependence on fossil fuels, multilateral environmental agreements to reduce emissions (FCCC, Kyoto), and actions to increase absorption of $\mathrm{CO}_{2}$ (afforestation). They also include policies that reduce the cost of mitigation (the Kyoto mechanisms: carbon trading, Joint Implementation, the Clean Development Mechanism and the European Bubble).

Adaptation, on the other hand, comprises defensive expenditures designed to reduce the cost of climate change if it happens. Examples of adaptation include construction of coastal and estuarine defences or the 'managed retreat' of coastlines to adapt to sea-level rise. They include the strengthening or relocation of infrastructure and industrial, commercial or domestic structures to adapt to the increased threat of storm damage, and other local features of global warming. Other examples involve change in water impoundment, water storage and water use to adapt to change in hydrological regimes; change in land use, especially change in crop and livestock mixes to adapt to changes in temperature and precipitation regimes; change in pesticide or irrigation regimes to adapt to change in the natural range of pests and pathogens; and change in public-health regimes to adapt to change in the distribution of human pathogens. Adaptation also includes the relocation of human populations in response to all of the above. Finally, it includes actions that either spread the risks of climate change through insurance, securitize the risks (e.g. catastrophe bonds) or reduce the cost of adaptation.

The optimal balance between mitigation and adaptation as response options to the prospect of climate change depends on their relative costs and benefits. There is certainly disagreement about the extent to which problems of this sort are amenable to benefit-cost analysis (e.g. Ekins 2000; Spash 1994). However, as Pearce (2003) and Tol (2003) point out, providing that the variance in the net benefits of climate-change control are finite, any set of response options is in principle amenable to benefit-cost analysis. For a number of reasons, mitigation is seldom regarded as a better option than adaptation. Part of the explanation for this is that mitigation is in the nature of a public good. To the extent that carbon emitted is perfectly mixed in the general circulation system, mitigating behaviour at any one location offers benefits to all. This provides every individual and every country with an incentive to free-ride on the efforts of others. The basic problem is quite simple. Each country will take into account the benefits its actions confer on the citizens of that country, not the benefits its actions confer on the citizens of other countries. These are ignored in the benefitcost calculations of each country. Suppose that the welfare of the $i$ th country depends on expenditures both on mitigation (reductions in carbon emissions), $y^{i}$, and adaptation, a private good, $x^{i}$. Since total reductions in emissions are the sum of reductions by each country, we have $U^{i}(\cdot)=U^{i}\left(x^{i}, y^{i}, Y\right)$, where $Y=y^{1}+\cdots+y^{i}+\cdots+y^{n}$. Taking $x^{i}$ to be the numeraire, $w$ to be the cost of emissions reductions in terms of the cost of adaptation, and $M^{i}$ to be a measure of the resources available, the 
problem for the $i$ th country is the following:

$$
\max _{x^{i}, y^{i}} U^{i}(\cdot)=U^{i}\left(x^{i}, y^{i}, Y \mid x^{i}+w y^{i}=I^{i}\right) .
$$

The first-order necessary conditions for the maximization of this problem require that $\partial U^{i} / \partial x^{i}-\lambda=0$, and that

$$
\frac{\partial U^{i}}{\partial y^{i}}+\left(\frac{\partial U^{i}}{\partial Y}\right)\left(\frac{\partial Y}{\partial y^{i}}\right)-\lambda w=0
$$

implying that

$$
\frac{\partial U^{i} / \partial y^{i}}{\partial U^{i} / \partial x^{i}}=w-\frac{\partial U^{i} / \partial Y}{\partial U^{i} / \partial x^{i}} \frac{\partial Y}{\partial y^{i}} .
$$

The $i$ th country will maximize its well-being if it equates the marginal rate of substitution between mitigation and adaptation with the marginal cost. If we now take the global problem to be

$$
\max _{x^{i}, y^{i}} U=U\left(U^{1}, U^{2}, \ldots, U^{n} \mid \sum_{i} x^{i}+w \sum_{i} y^{i}=\sum_{i} I^{i}\right),
$$

it is straightforward to verify that the first-order necessary conditions require that

$$
\frac{\partial U^{i} / \partial y^{i}}{\partial U^{i} / \partial x^{i}}=w-\sum_{i} \frac{\partial U^{i} / \partial Y}{\partial U^{i} / \partial x^{i}} \frac{\partial Y}{\partial y^{i}}
$$

the extra terms capturing the benefit that mitigation by the $i$ th country confers on the rest of the world. Since the $i$ th country cannot capture the value of these benefits, they will not take them into account in their mitigation decisions.

The problems posed by the public-good nature of mitigation for international cooperation have been exhaustively analysed by, amongst others, Barrett (1990, 1999), Carraro \& Siniscalco (1998), Carraro (2002) and Pearson (2000), and taken together with the Nordhaus results discussed below go a long way to explaining the failure of the Kyoto Protocol (and the success of the Montreal Protocol).

An additional problem with climate change is the long time delay between an action and its payoff. The $i$ th country will select its climate-change policy from the set of all investment options that yield a positive expected present value. The expected present social value (PSV) of the $j$ th alternative is given by

$$
\operatorname{PSV}^{j}=\sum_{t=0}^{T} \sum_{h=0}^{n} p_{h t}^{j} q_{h t}^{j}\left(\frac{1}{1+\delta}\right)^{t}
$$

in which $\left(q_{1 t}^{j}, \ldots, q_{n t}^{j}\right)$ is the set of $n$ outcomes (in terms of net benefits accruing to the decision maker or the community represented by the decision maker) of the $j$ th alternative in period $t,\left(p_{1 t}^{j}, \ldots, p_{n t}^{j}\right)$ is the set of probabilities attached to each outcome, $T$ is the time horizon over which the stream of expected net benefits is calculated, and $\delta$ is the rate of discount.

Positive discount rates not only reduce the weight attached to future costs and benefits, they also act to screen uncertainty out of the information relevant to the decision-making process. Since uncertainty tends to increase the further into the 
Table 1. Estimates of the aggregate cost of gradual warming (Pearce 2003)

Nordhaus \& Boyer (2000) Mendelsohn et al. (1996) Tol (2002a,b)

$2.5{ }^{\circ} \mathrm{C}$

$-1.5 \%$ change

in world GNP $2.5^{\circ} \mathrm{C}$

$+0.1 \%$ change

in world GNP $1.0^{\circ} \mathrm{C}$

$+2.3 \%$ change

in world GNP

future the decision maker projects the costs and benefits of an action, higher discount rates will assign less weight to more uncertain outcomes. An implication of this is that decisions taken on the basis of higher discount rates will yield more unexpected effects than decisions taken on the basis of lower discount rates. The effect of discounting is both to increase the potential for unexpected future costs, and to eliminate those costs from consideration.

Because the circulation system is a global public good, because carbon is a stock pollutant and it takes considerable time for mitigation to yield benefits, and because those benefits are uncertain, mitigation expenditures generally offer a poor return. These studies have been heavily influenced by the set of models used to generate estimates of the costs and benefits of climate change developed by Nordhaus (1977, 1994), Nordhaus \& Yang (1996) and Nordhaus \& Boyer (2000). Nordhaus's conclusions favour only modest mitigation efforts, and stem from model predictions that include continued growth in world output despite the moderating effect of climate change. Those who have reached different conclusions using similar models have done so either because they have chosen to apply different discount rates (Cline 1992) or have found different levels of damage (Roughgarden \& Schneider 1999) or have included different mitigation mechanisms. The inclusion of research and development, for example, turns out to be potentially important. Work by Buonanno et al. (2001) using Nordhaus's own model but with Goulder \& Mathai's (2000) technical change alters the balance in favour of mitigation. Nevertheless, the fact remains that Nordhaus's conclusions command widespread respect and have driven climatechange policy, particularly in the US.

The estimates generated by the body of literature usually refer to the cost (in terms of the percentage change in world gross national product (GNP)) of some arbitrary change in either $\mathrm{CO}_{2}$ concentrations or mean temperature, under different response options. Nordhaus's estimates are far from being the most optimistic. Table 1 reports three estimates, two of which suggest that global GNP will increase with climate change.

Part of the explanation for the difference lies in the assumptions made about the way in which mitigation is implemented. There is a good deal of evidence to show that the Kyoto mechanisms will substantially reduce the cost of mitigation (Bosello et al. 2000; Carraro 2002; IPCC 2001; Goulder \& Mathai 2000; Buonanno et al. 2001). Pearce et al. (1996) recorded the following cost savings due to Joint Implementation (see table 2).

However, by far the most important difference is the assumption made about the balance between adaptation and mitigation in the response options considered. In principle, the optimal strategy is that which balances the marginal costs and benefits of alternative climate-change actions. Where climate-change options include both mitigation and adaptation, the optimal strategy will balance the marginal costs of 
Table 2. Carbon reduction through Joint Implementation by sector (Pearce et al. 1996) $\left(\$ \mathrm{tC}^{-1}\right.$, US dollars ( $\$$ denotes US dollars throughout paper) per tonne of carbon equivalent saved. $\mathrm{n} / \mathrm{a}$, not available. Estimated marginal damages of global warming equals $\mathrm{ca} . \$ 30 \mathrm{tC}^{-1}$.)

\begin{tabular}{lcccc}
\hline investment sector & $\begin{array}{c}\text { number of } \\
\text { projects }\end{array}$ & $\begin{array}{c}\text { average cost } \\
\left(\$ \mathrm{tC}^{-1} \text { saved }\right)\end{array}$ & $\begin{array}{c}\text { highest cost } \\
\left(\$ \mathrm{tC}^{-1} \text { saved }\right)\end{array}$ & $\begin{array}{c}\text { lowest cost } \\
\left(\$ \mathrm{tC}^{-1} \text { saved }\right)\end{array}$ \\
\hline \multicolumn{1}{c}{ energy sector } & & & & \\
renewables & 36 & 71.5 & 861.9 & 19.7 \\
energy efficiency & 24 & 148.0 & 653.3 & 2.3 \\
fugitive gas capture & 2 & 180.0 & 384.6 & 0.04 \\
fuel switching & 3 & 204.0 & 583.6 & 8.5 \\
\hline \multicolumn{1}{l}{ land-use sector } & & & & \\
afforestation & 2 & 1.2 & 3.0 & 0.1 \\
forest conservation & 4 & 5.8 & 12.1 & 5.4 \\
forest restoration & 2 & 39.2 & 242.4 & $\mathrm{n} / \mathrm{a}$ \\
agriculture & 1 & $\mathrm{n} / \mathrm{a}$ & $\mathrm{n} / \mathrm{a}$ & \\
\hline
\end{tabular}

the two alternatives. Moreover, since mitigation influences the probability of climate change, whereas adaptation does not, the optimal strategy will allow for interactions between the two sets of alternatives.

Carraro (2002) notes that climate-change economists have paid relatively little attention to the alternative of adaptation (though see Plambeck et al. (1997) and Plambeck \& Hope (1996)). However, it does have a number of features that influence the benefit-cost calculus. First, adaptation represents a local response to global change, where global change is itself treated as exogenous to the problem. The benefits of adaptation expenditures are captured almost entirely by the decision maker, or the community represented by the decision maker in the case of public goods. This implies that private individuals or firms have a much stronger incentive to undertake private adaptation actions than they have to undertake private mitigation actions. Furthermore, adaptation public goods such as sea defences or public-health regimes allow free-riding by the local population, but do not in general offer significant benefits to the international community. No country has an incentive to free-ride on the adaptation expenditures by another country, and all countries are able to capture the benefits of adaptation.

Second, the timing of adaptation expenditures is less constrained by the dynamics of the circulation system than the timing of mitigation expenditures. Adaptation actions do not need to be undertaken so far in advance of climate change to deliver benefits, indeed they may even take the form of reactions to climate change after the fact. It is not therefore surprising that adaptation is the best private response to climate change under most of the scenarios painted by the IPCC.

Third, since adaptation is a local/national option, it is constrained by the same factors that constrain all local/national expenditures. International inequality in the distribution of income and assets is reflected in differences in the level of self-protection against the effects of climatic variability.

Pearce (2003) summarizes the impact of adaptation by contrasting estimates of the marginal damage cost of current carbon emissions deriving from models that do 
Table 3. The marginal damage cost of carbon emissions under gradual warming with and without adaptation (Pearce 2003)

\begin{tabular}{ccc}
\hline $\begin{array}{c}\text { constant rate } \\
\text { of discount }\end{array}$ & $\begin{array}{c}\text { estimates based } \\
\text { on mitigation plus } \\
\text { adaptation }\left(\$ \mathrm{tC}^{-1}\right)\end{array}$ & $\begin{array}{c}\text { estimates based } \\
\text { on mitigation } \\
\text { only }\left(\$ \mathrm{tC}^{-1}\right)\end{array}$ \\
\hline $3 \%$ & +4 to +9 & +40 to +50 \\
$5 \%$ & -7 to +15 & +20 to +37 \\
\hline
\end{tabular}

and do not allow for adaptation - the Mendelsohn estimate in table 1 does allow for adaptation. The inclusion of adaptation yields much lower estimates of the marginal damage costs of carbon emissions (table 3).

Although adaptation substantially lowers the cost of climate change at the global level, it turns out that benefits of adaptation are very sensitive to income. Consider, for example, the effect of extreme climatic events: hurricanes, cyclones, storms, floods and droughts. Both the frequency and the severity of 'natural disasters' affect low-income countries disproportionately. In the last decade of the 20th century, for example, $94 \%$ of all natural disasters and $97 \%$ of deaths due to natural disasters occurred in low-income countries. Indeed, around two-thirds of all disaster-related deaths occurred in South Asia alone. Moreover, the cost of natural disasters as a proportion of GDP was 20\% higher in low-income than in high-income economies (World Bank 2001). The disproportionate impact of extreme events on low-income economies is due less to environmental factors than to the extreme vulnerability of the poorest sections of those communities. The poorest in society are often the most exposed to disaster risk. They live in densely populated squatter settlements in the most vulnerable locations, e.g. on steeply sloping land, along river banks and flood plains, or on the margins of wetlands. Infrastructure in such locations is rudimentary or nonexistent. The capacity both to avoid and to recover from disasters is quite limited, and the probability that people affected by disaster will lose their lives or livelihoods is often high. People affected by natural disasters in low-income countries are reckoned by the International Red Cross/Red Crescent to be four times more likely to die than people affected by natural disasters in high-income countries. In other words, the cost of extreme events reflects not just environmental conditions, but the global distribution of wealth and income. People in poor countries are effectively much less able to control the damage done by such events (World Bank 2001).

As an indication of the importance of differences in adaptive capacity to deal with the consequences of climate change, table 4 reports estimates of the differences in the benchmark cost of climate change between developed and developing countries in studies making greater (Mendelsohn) or lesser (Nordhaus) allowance for adaptive responses. Except in one case, adaptation is not enough to protect developing countries from the negative consequences of climate change.

\section{Abruptness and uncertainty}

These exercises largely ignore the uncertainty associated with climate change. If abrupt climate change means a change of state, it involves a range of potential biogeophysical effects whose features and distribution may be fundamentally uncertain. The standard approach to the evaluation of activities with risky outcomes, the 
Table 4. Differences in benchmark cost of climate change between developed and developing countries (DCs and LDCs; percentage change in GNP) (Pearce 2003)

\begin{tabular}{lccc}
\hline & $\begin{array}{c}\text { Mendelsohn et al. (1996) } \\
1.5{ }^{\circ} \mathrm{C}\end{array}$ & $\begin{array}{r}\text { Mendelsohn et al. (1996) } \\
2.5{ }^{\circ} \mathrm{C}\end{array}$ & $\begin{array}{c}\text { Nordhaus \& Boyer (2000) } \\
2.5{ }^{\circ} \mathrm{C}\end{array}$ \\
\hline DCs & $+0.12 \%$ & $+0.03 \%$ & -0.5 to $+0.4 \%$ \\
LDCs & $+0.05 \%$ & $-0.17 \%$ & -0.2 to $-4.9 \%$ \\
\hline
\end{tabular}

expected utility approach - reflected in expected benefit-cost analysis - may not be helpful in these circumstances. This approach supposes that 'uncertainty' takes the form of 'risk', i.e. that both the set of all possible outcomes and the probability distribution of those outcomes are known. By contrast, fundamental uncertainty implies that either the set of all possible outcomes of an action or the probability distribution of the outcomes is unknown (Katzner 1989, 1998).

The standard approach implies that the attractiveness of a gamble is evaluated in terms of the expected utility associated with the payoffs of that gamble. This implies a preference function of the form

$$
V(p, x)=\sum_{i=1}^{n} p_{i t} u\left(q_{i t}\right),
$$

where $u(\cdot)$ is a von Neumann-Morgenstern utility function defined on the set of outcomes, $\left(q_{1 t}, \ldots, q_{n t}\right)$, and the corresponding probabilities, $\left(p_{1 t}, \ldots, p_{n t}\right)$. The underlying utility function assumes that peoples' preferences between risky prospects have certain characteristics. Specifically, it is assumed that preferences are transitive, continuous and independent.

Expected utility provides a logical, internally consistent approach to decisionmaking under risk that is now deeply embedded in economic theory. There are, however, good reasons why the expected utility approach is inappropriate as a general theory of decision-making under fundamental uncertainty. By construction, von Neumann-Morgenstern utilities are insensitive to low-probability events. It has been argued that this makes the expected utility approach inadequate for evaluating catastrophic risk (Chichilnisky 1998). At the same time there is systematic evidence that people do not treat catastrophic risk in this way. In particular, the probability of a 'very unlikely' outcome tends either to be overestimated or to be equated to zero. The deviation of the perceived from the actual risk in these cases generally depends on the value of the outcome. Moreover, this occurs even in well-functioning risk markets.

In liability insurance markets, for example, in cases where the probability is very low but the potential loss is very high, insurers demand a risk premium that makes the rates exceed the expected losses. At the same time, the insured are willing to pay less than predicted by expected utility calculations (Katzman 1988). Similarly, people asked to estimate the probability of deaths from different causes tend to underestimate deaths from frequent causes, but to overestimate deaths from infrequent causes (Pigeon et al. 1992). McDaniels et al. (1992) describe this as a 'dread' effect. They argue that it causes people to overestimate the risks of high-'dread' events outside their control, such as nuclear or toxic waste accidents; and to underestimate the risks of low-'dread' events in their control, such as car accidents. 
A second empirical problem for expected utility theory is that decision makers have been shown to have different attitudes to gains and losses. Two examples are known as the 'reference-point effect' and 'preference reversal'. Empirical research has shown that individual decisions are frequently based on a reference point, often represented by the initial endowment of the decision maker or the status quo. Kahneman \& Tversky (1979) found that the disutility that people experienced from a loss of some magnitude often outweighed the utility from a gain of the same magnitude. This implies that the utility function may be steeper for losses than for gains. Experiments conducted at around the same time involving one prospect that offered a high probability of a small gain and another prospect that offered a low probability of a large gain showed something quite similar. People systematically value the riskfree small-gain option over the risky large-gain option when invited to express their willingness to pay, but value the risky large-gain option over the risk-free small-gain option when invited to express their willingness to accept compensation for the loss of options (Mowen \& Gentry 1980).

Decision-making under fundamental uncertainty is addressed in different ways in the literature. One approach, due to Savage (1954), assumes that people form subjective opinions about the likelihood of the future consequences of their decisions. That is, the probability distribution of outcomes is subjective. It reflects people's beliefs about the likelihood attached to the possible outcomes of their actions. Where they have no idea about the probability distribution of the outcomes they believe may happen, they are assumed to assign equal probabilities to all outcomes. This is the principle of indifference or insufficient reason (Arrow \& Hurwicz 1972).

A second approach to decision-making under uncertainty goes even further away from the idea that people make decisions based on the probabilities attached to the outcomes of their behaviour. This approach, due to Shackle $(1955,1969)$ but developed by Vickers (1978) and Katzner (1989, 1998), assumes that decision makers do not formally work with estimates of the probability distribution of outcomes, but with the degree of disbelief or potential surprise associated with each outcome.

A third approach assumes that the underlying probability distribution of outcomes is known, but that decision makers weight the various outcomes of their actions (Fishburn 1988). Such weighted preferences over outcomes can be represented by the function

$$
V(p, x, \Psi)=\sum_{i} p_{i t} g\left(q_{i t}, \Psi_{t}\right) u\left(x_{i t}\right),
$$

where $g\left(q_{i t}, \Psi_{t}\right)$ is the weighting function, which depends both on the value of the outcomes, $q_{i t}$, and the state of knowledge at time $t, \Psi_{t}$. If the weights attached to all outcomes are identical, this reduces to standard expected utility theory. The weights attached to the different outcomes may be interpreted as measures of the decision maker's understanding of or belief in the underlying probability distribution. Hence the approach can capture at least one dimension of decision-making under uncertainty.

Most weighted utility approaches do not connect the weights with people's understanding of the underlying distribution, but with their perception of the relative importance of the outcome. An early example of a probability weighting function was Quiggin's (1982) rank-dependent expected-utility approach. This allowed the weight attached to outcomes with the same probability to vary according to how good or bad the outcome was. Quiggin (1982) proposed that decision makers would 


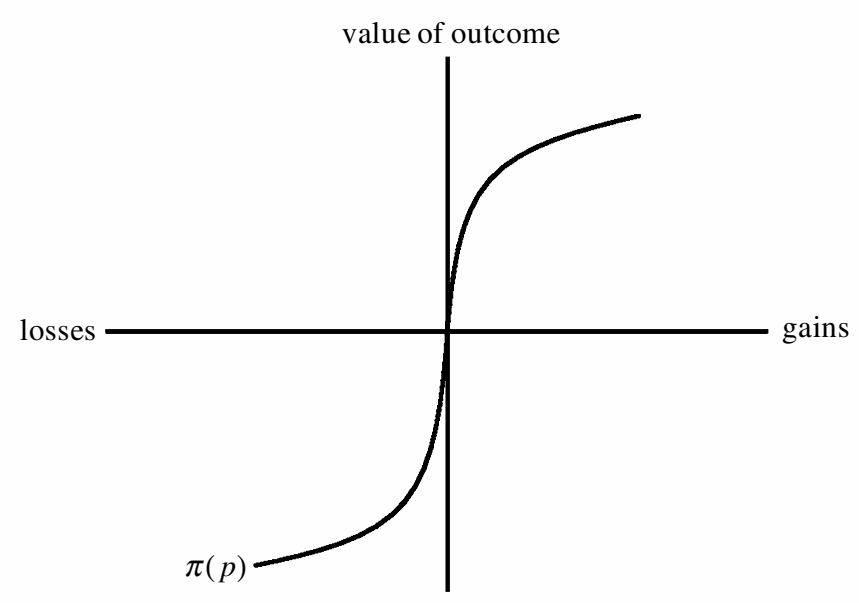

Figure 1. Probability weighting function.

overweight low-probability outcomes and underweight high-probability outcomes. Subsequently, Starmer \& Sugden (1989) and Tversky \& Kahneman (1992) suggested that the probability weights might vary around a reference point. Specifically, they suggested that the weighting function might be concave for gains and convex for losses (see figure 1).

While this reflects the asymmetry that has been observed between people's perceptions of gains and losses, it also reflects diminishing sensitivity. That is to say, people assign greater weight to small changes around a reference point than to large changes. If the reference point is the status quo, it implies extreme sensitivity to minor losses and gains, but insensitivity to major losses or gains. This might seem to be inconsistent with the weights implicit in a precautionary approach, but it is important to recall that the reference point is arbitrary. As Starmer (2000) points out, the reference points can just as easily be the endpoints of the probability scale. Certainly, there is growing appreciation of the importance of understanding reference points if we are to understand economic behaviour in a risky environment (Heath et al. 1999).

The characteristics of abruptness that affect the decision-making process relate both to the existence of threshold effects and to the time taken for the effects to be realized. Abrupt climate change implies that the system flips from one state to another in a relatively short period of time. The change of state will typically be unprecedented (at least in terms of the human historical record). It may also be irreversible, and its effect on human well-being may be very high. Since neither the set of outcomes nor the probability distribution of those outcomes may be known, the problem is one of decision-making under uncertainty.

Where a change of state involves fundamental uncertainty, potential irreversibility and at least the possibility of high social costs, decision makers would be expected to assign it a high weight in the decision process. This is consistent with a precautionary approach. Precautionary action requires the commitment of resources now to safeguard against the potentially severe but uncertain future effects of decisions until the decision maker has been able to learn about the consequences of those decisions. This holds for actions whose outcomes are generally known, but are unfamiliar 
to the decision maker. It holds even more strongly for actions whose outcomes are unknown.

\section{Discussion}

Implementation of the precautionary principle depends on information that triggers precautionary action. Extreme, unique, rare and irreversible events all share the characteristics that they have either no or only a few historical precedents, and that their effects may be quite novel. They involve losses or gains that are qualitatively different from what has gone before. Indeed, in all complex systems, events can trigger changes that are unprecedented (think of bifurcation points in chaotic systems, or unstable regions between different attractors in a system with multiple equilibria). In such cases it may not be possible to predict a probability distribution of outcomes with confidence. Nevertheless, decision makers need information on which to act. Identifying such information is the first element of a precautionary approach. Historic examples of such tests include 'scientifically based suspicion', 'reasonable grounds for concern' and the 'balance of evidence' (Harremoës et al. 2001). All are based on data that fail standard tests of scientific proof, but nevertheless provide a basis for decision-making. They are 'early warning signs' rather than conclusive proof.

There are numerous examples of scientific early warnings on other environmental problems that were ignored by decision makers. The contamination of the Great Lakes by organochlorine compounds is a case in point (Gilbertson 2001). Once it had been shown that the lakes contained organochlorine pesticides in the 1960s, research quickly followed showing the bioaccumulation in birds of dichlorodiphenyl trichloroethane (DDT) and polychlorinated biphenyls (PCBs). The accumulation of evidence against DDT led to its banning both in the US and Canada by the early 1970s. But action against PCBs has been both slower and weaker. A series of studies of the human-development impacts of exposure to PCBs showed significant development deficits, but the evidence has been regarded as too weak to justify precautionary action. Current levels of PCBs in the Great Lakes are still two orders of magnitude higher than the level established to protect humans against cancer risk (Gilbertson 2001).

In the case of climate, the only credible sources of information are the climate models. Modelling offers a transparent basis for predictions that, if severe enough to attract the decision maker's attention, should stimulate precautionary measures. Where risk estimates are based on model simulations rather than laboratory experiments, the test of admissibility is whether the model assumptions (or axioms) accord with reality, rather than the replication of experiments designed to test the model predictions. The point has already been made that a non-probabilistic scenario approach is not well suited to the identification of the consequences of mitigation relative to adaptation. The evaluation of the consequences of climate-change policy options requires a probabilistic approach that is capable of factoring in feedbacks between the social and the natural systems.

An important move in this direction is the development of techniques for delivering a more complete representation of the uncertainties relating to climate models and the predictability of climate change. Using large 'perturbed-physics' ensemble simulations, it will soon become possible to quantify uncertainty in model parameter, 
emissions and climate-system space. This will make it possible to construct confidence intervals around climate-change predictions at a relatively high spatial resolution. Since the 'downscaling' of GCM information using higher-resolution regional climate models translates global flows from GCMs into local flows using fundamental physics, it is expected to be able to cope with nonlinearity in the local response to large-scale forcing. That is, it is expected to be able to predict regional regime shifts such as the interruption of the THC. If abrupt regional climate change is in fact generated as an outcome of the new set of models, this should provide sufficient 'early warning' to trigger precautionary action.

A crucial element of any precautionary approach is the mechanism by which the decision maker learns about the probability distribution of outcomes. Since uncertainty implies that there is scope for learning (although learning does not necessarily reduce uncertainty), every problem that is a candidate for a precautionary approach is also a candidate for learning. Precautionary action implies a mechanism for learning, or for updating the information on which decisions are taken since expectations about the payoff to different outcomes are conditional on the state of knowledge, and are therefore revised as the state of knowledge changes.

A precautionary approach that does not embed learning fails to address the central problem of uncertainty. Learning in this sense means that the state of knowledge changes over time. In the preference function $V(p, x, \Psi)$, learning implies that $\Psi_{t}<\Psi_{t+1}$. If $\Psi_{t} \geqslant \Psi_{t+1}$ then society is either losing knowledge or learning nothing. Learning is a necessary (but not sufficient) condition for a reduction in uncertainty. The learning process depends on either the passive accumulation of evidence or research to prove the existence or non-existence of harmful effects. Either time proves the effect, or repeated tests falsify the null hypothesis. Since a precautionary approach excludes the passive accumulation of evidence, precautionary learning depends on research.

Precautionary action may involve both mitigation and adaptation, depending on the degree to which current actions can influence either the probability of change or the cost of change. Precautionary responses to abrupt change, such as the interruption of the thermohaline circulation, might therefore include either mitigation in the form of reduced emissions (if that is shown to have an impact on the probability of the event) or adaptation in the form of investment in infrastructure or land-use restrictions that have a long lead time. The choice between them will depend on the relative net benefits of the options, and that will reflect human capacity to influence the outcome. Learning, in this case, deepens understanding both about the likelihood of different environmental outcomes, and about the socially optimal response to those outcomes.

While the best-response option does depend on the details of the problem at hand, there are some general points that may be made about the implications of abruptness for the relative net benefits of mitigation and adaptation. I close with these. In general, we would expect the possibility of major regime shifts to alter the weighted relative net benefits of mitigation and adaptation in favour of mitigation. There are three reasons for this. First, although the USNRC definition of abrupt climate change in terms of the capacity to adapt may be too restrictive, it is reasonable to suppose

(i) that abrupt climate change will increase the costs of adaptation, and 
(ii) that this increase in costs may be permanent due to the irreversibility of the change in state or, if not permanent, at least very long lasting.

The effect of this will be to reduce the relative net benefits of adaptation over mitigation.

Second, if abrupt change implies that the time delay between emissions and climate change is reduced, it also implies that the time delay between mitigation and the benefits accruing from mitigation will be reduced. This should increase the present value of the net benefits of mitigation. If it also means that the time delay between mitigation and adaptation actions will be reduced, so will the private advantages of adaptation over mitigation.

Third, if the change in state associated with abrupt climate change reduces the expected rate of growth in consumption, it will also reduce the rate at which future costs and benefits should be discounted. This will favour mitigation actions with a longer-term payoff. To see this, note that the efficient discount rate depends on the consumption rate of interest, which is defined by the expected rate of growth in per capita consumption. Positive expected rates of consumption growth 'authorize' the discounting of future costs and benefits. The rate of discount applicable to far-future effects should accordingly reflect expectations about far-future consumption growth. If the rate of growth in consumption were expected to fall over time, as it might under abrupt climate change, then the efficient discount rate should also fall over time (Dasgupta 2001). In these circumstances, far-future costs would feature much more strongly in the calculus of present social value than under constant discounting. In most existing models of the net benefits of mitigation, the discount rate is assumed to be constant over the whole time horizon.

For all three reasons, the prospect of abrupt climate change may be expected to lead policy makers to allocate more resources to mitigation and less to adaptation. This effect is exaggerated by the impact of abrupt climate change on the uncertainty attached to the two response options. If mitigation is sufficient to assure that the system remains in the existing state, and if adaptation assures an unprecedented change of state, the payoffs to mitigation policies will be less uncertain than the payoffs to adaptation policies. Moreover, if the change of state is irreversible or only slowly reversible, the costs associated with it will be either permanent or long term.

This said, any local or regional regime shift may well be driven by emissions elsewhere. There may, for example, be very limited scope for European mitigation of the risk of interruption of the thermohaline circulation, since it is a local effect of a change in global conditions. Mitigation, in this case, requires global cooperation and hence is affected by all the factors that militate against global cooperation. In the absence of global cooperation, adaptation may be the only feasible response option.

\section{References}

Arrow, K. J. \& Hurwicz, L. 1972 An optimality criterion for decision-making under ignorance. In Uncertainty and expectations in economics (ed. C. F. Carter \& J. L. Ford), pp. 1-11. Oxford: Blackwell.

Barrett, S. 1990 The problem of global environmental protection. Oxf. Rev. Econ. Policy 6, $68-79$. 
Barrett, S. 1999 A theory of full international environmental cooperation. J. Theor. Policy 11, 519-541.

Bosello, F., Carraro, C. \& Galeotti, M. 2000 The double dividend issue: modelling strategies and empirical findings. Environ. Dev. Econ. 6, 9-45.

Buonanno, P., Carraro, C. \& Galeotti, M. 2001 Endogenous induced technical change and the cost of Kyoto. FEEM Nota di Lavoro, no 80.2000. Milan: Fondazione Eni Enrico Mattei.

Carraro, C. 2002 Climate change policy: models, controversies and strategies. In The International Yearbook of Environmental and Resource Economics 2002/2003 (ed. T. Tietenberg \& H. Folmer), pp. 1-65. Cheltenham: Elgar.

Carraro, C. \& Siniscalco, D. 1998 International environmental agreements: incentives and political economy. Eur. Econ. Rev. 42, 561-572.

Chichilnisky, G. 1998 The economics of global environmental risks. In The International Yearbook of Environmental and Resource Economics 1998/1999 (ed. T. Tietenberg \& H. Folmer), pp. 235-278. Cheltenham: Elgar.

Cline, W. R. 1992 The economics of global warming. Washington, DC: Institute for International Economics.

Dasgupta, P. 2001 Human well-being and the natural environment. Oxford University Press.

Ekins, P. 2000 Costs, benefits and sustainability in decision-making, with special reference to global warming. Int. J. Sust. Dev. 3, 315-333.

Fishburn, P. 1988 Nonlinear preference and utility theory. Brighton: Wheatsheaf.

Gilbertson, M. 2001 The precautionary principle and early warnings of chemical contamination of the Great Lakes. In Late lessons from early warnings: the precautionary principle. Environment issue report no. 22 (ed. P. Harremoës, D. Gee, M. MacGarvin, A. Stirling, J. Keys, B. Wynne \& S. Guedes Vaz), pp. 126-134. Copenhagen: European Environment Agency.

Goulder, L. H. \& Mathai, K. 2000 Optimal $\mathrm{CO}_{2}$ abatement in the presence of induced technological change. J. Environ. Econ. Mngmt 39, 1-38.

Harremoës, P., Gee, D., MacGarvin, M., Stirling, A., Keys, J., Wynne, B. \& Guedes Vaz, S. (eds) 2001 Late lessons from early warnings: the precautionary principle. Environment issue report no. 22. Copenhagen: European Environment Agency.

Heath, C., Huddart, S. \& Lang, M. 1999 Psychological factors and stock option exercise. Q. J. Econ. 114, 601-627.

IPCC 2001 Third Assessment Report and Summary for Policy Makers. Cambridge University Press.

Kahneman, D. \& Tversky, A. 1979 Prospect theory: an analysis of decision making under risk. Econometrica 47, 263-291.

Katzman, M. T. 1988 Pollution liability insurance and catastrophic environmental risk. J. Risk Ins. 55, 75-100.

Katzner, D. W. 1989 The comparative statics of the Shackle-Vickers approach to decisionmaking in ignorance. In Studies in the economics of uncertainty: in honour of Joseph Hadar (ed. T. B. Fomby \& T. K. Seo). Springer.

Katzner, D. W. 1998 Time, ignorance and uncertainty in economic models. Ann Arbor, MI: University of Michigan Press.

Kaul, I., Conceicao, P., le Goulven, K. \& Mendoza, R. U. (eds) 2003 Providing global public goods. Oxford University Press.

McDaniels, T., Kamlet, M. \& Fischer, G. 1992 Risk perception and the value of safety. Risk Analysis 12, 495-503.

Mendelsohn, R., Morrison, W., Schlesinger, M. \& Andronova, N. 1996 Global impact model for climate change. School of Forestry, Yale University, New Haven, CT, USA.

Mowen, J. C. \& Gentry, J. W. 1980 Investigation of the preference reversal phenomenon in a new product introduction task. J. Appl. Psychol. 65, 715-722. 
Nordhaus, W. D. 1977 Economic growth and climate: the carbon dioxide problem. Am. Econ. Rev. 67, 341-346.

Nordhaus, W. D. 1994 Managing the global commons: the economics of climate change. Cambridge, MA: MIT Press.

Nordhaus, W. D. \& Boyer, J. 2000 Warming the world: economic models of global warming. Cambridge, MA: MIT Press.

Nordhaus, W. D. \& Yang, Z. 1996 A regional dynamic general equilibrium model of alternative climate change strategies. Am. Econ. Rev. 86, 741-765.

Pearce, D. W. 2003 The social cost of carbon and its policy implications. Oxf. Rev. Econ. Policy (In the press.)

Pearce, D. W., Cline, W. R., Achanta, A., Fankhauser, S., Pachauri, R., Tol, R. \& Vellinga, P. 1996 The social costs of climate change: greenhouse damage and the benefits of control. In IPCC, Climate Change 1995: economic and social dimensions of climate change, pp. 183-224. Cambridge University Press.

Pearson, C. S. 2000 Economics and the global environment. Cambridge University Press.

Pigeon, N., Hood, C., Jones, D., Turner, B. \& Gibson, R. 1992 Risk perception. In Risk: analysis, perceptions and management. Report of a Royal Society Study Group. London: The Royal Society.

Plambeck, E. L. \& Hope, C. 1996 PAGE95: an updated valuation of the impacts of global warming. Energy Policy 24, 783-793.

Plambeck, E. L., Hope, C. \& Anderson, J. 1997 The PAGE95 model: integrating the science and economics of global warming. Energy Econ. 19, 77-101.

Quiggin, J. 1982 A theory of anticipated utility. J. Econ. Behav. Organ. 3, 323-343.

Roughgarden, T. \& Schneider, S. H. 1999 Climate change policy: quantifying uncertainties for damages and optimal carbon taxes. Energy Policy 27, 415-429.

Savage, L. J. 1954 The foundations of statistics. Wiley.

Shackle, G. L. S. 1955 Uncertainty in economics. Cambridge University Press.

Shackle, G. L. S. 1969 Decision, order and time in human affairs. Cambridge University Press.

Spash, C. 1994 Double $\mathrm{CO}_{2}$ and beyond: benefits, costs and compensation. Ecol. Econ. 10, $27-36$.

Starmer, C. 2000 Development in non-expected utility theory: the hunt for a descriptive theory of choice under risk. J. Econ. Lit. 38, 332-382.

Starmer, C. \& Sugden, R. 1989 Violations of the independence axiom in common ratio problems: an experimental test of some competing hypotheses. Ann. Operat. Res. 19, 79-102.

Tol, R. $2002 a$ Estimates of the damage costs of climate change. 1. Benchmark estimates. Environ. Resource Econ. 21, 47-73.

Tol, R. $2002 b$ Estimates of the damage costs of climate change. 2. Dynamic estimates. Environ. Resource Econ. 21, 135-160.

Tol, R. 2003 Is the uncertainty about climate change too large for expected cost-benefit analysis? Clim. Change. (In the press.)

Tversky, A. \& Kahneman, D. 1992 Advances in prospect theory: cumulative representation of uncertainty. J. Risk. Uncert. 5, 297-323.

USNRC 2002 (US National Research Council) Abrupt climate change: inevitable surprises. Washington, DC: National Academies Press.

Vickers, D. 1978 Financial markets in the capitalist process. Philadelphia, PA: University of Pennsylvania Press.

World Bank 2001 World development report 2000/2001: attacking poverty. Oxford University Press. 


\section{Discussion}

J. M. Ziman (University of Bristol, UK). Do economists not have any intellectual machinery for factoring into their analysis the disbenefits to other people of actions on which they are making cost-benefit calculations? For example, how would, say, the possible complete flooding of Bangladesh be allowed for in an analysis of climate change on the UK?

C. Perrings. An economic analysis of the net impacts of GHG emissions can be made at many different levels. It would be possible, for example, to calculate the net benefits of UK policy options to people within the UK only. However, this would be a strictly partial analysis, since it would exclude the impacts of UK policy on people in other countries. A more complete analysis would take into account the impact of UK decisions on people across the globe. If UK policy increases the likelihood that Bangladesh will be inundated, that is indeed a relevant cost and should be taken into account. What stands in the way of such calculations is not economics. It is science. We are not currently able to connect policies in one region with the likelihood of changes in another region.

This said, recent developments in climate modelling will help economists to develop more complete estimates of the net benefits of different policy options. We expect to be able to represent the likelihood of climate change in terms of probabilistic climate predictions at high spatial resolution. The development of empirical downscaling methodologies will enable rapid and efficient probabilistic predictions of local climate change from large-ensemble GCM data. This should make it possible to track the impacts at any one location of changes induced by GHG emissions at other locations.

CH. Körner (Institute of Botany, University of Basel, Switzerland). I guess those cost and benefit calculations are based on climate-change consequence only. A Swiss expert panel (http://www.proclim.ch/OcCC/reports/Sekundaernutzen-e.html) estimated that the secondary benefits of fossil fuel savings could be such that they could be beneficial even if there were no climate change. These benefits refer to national economies (in a non-fossil fuel exporting country) and health benefits (any $\mathrm{CO}_{2}$ release is coupled to pollution).

C. Perrings. 'Secondary benefits' of mitigation measures are not explicitly included in those calculations. However, since the calculations are based on expected changes in world GDP associated with mitigation strategies, they should include any effects of this sort. If the current benefits of mitigation were indeed sufficient to offset the loss of current output, and if climate change does have negative rather than positive effects on global output, this should favour mitigation over adaptation strategies. Most of the existing estimates of the net benefits of mitigation relative to adaptation find the opposite.

N. Crumpton (Friends of the Earth Cymru, UK). Are the researchers who calculated the net benefits of mitigation aware of the latest developments in costcompetitive renewable-energy technologies? There are economic gains in deploying such technologies in most countries even if there were no GHG imperatives.

C. Perrings. Most existing studies find that at current levels of demand, and current estimates of the marginal damage cost of GHG emissions, there is limited scope for substitution of renewable for non-renewable energy sources. In principle, 
such findings are based on the best available knowledge of the marginal cost of different energy options. Of course, developments that reduce the marginal cost of particular technologies might change that conclusion. So too would evidence that the marginal damage cost of emissions was much higher than previously thought. The UK Treasury's estimate of marginal damage costs of emissions is higher than that of most other organizations. But even with that estimate, there does not currently seem to be a great deal of scope to substitute renewable for non-renewable energy sources. 